\title{
The Pleasures and Perils of Darwinizing Culture (with phylogenies)
}

\author{
Russell D. Gray, Simon J. Greenhill and Robert M. Ross \\ Department of Psychology \\ University of Auckland \\ Auckland \\ New Zealand \\ Correspondence to: rd.gray@auckland.ac.nz
}

To appear in Biological Theory, Volume 2 (4).

\begin{abstract}
Current debates about "Darwinizing culture" have typically focused on the validity of memetics. In this paper we argue that meme-like inheritance is not a necessary requirement for descent with modification. We suggest that an alternative and more productive way of Darwinizing culture can be found in the application of phylogenetic methods. We review recent work on cultural phylogenetics and outline six fundamental questions that can be answered using the power and precision of quantitative phylogenetic methods. However, cultural evolution, like biological evolution, is often far from tree-like. We discuss the problems reticulate evolution can cause for phylogenetic analyses and suggest ways in which these problems can be overcome. Our solutions involve a combination of new methods for the study of cultural evolution (network construction, reconciliation analysis, and Bayesian mixture models), and the triangulation of different lines of historical evidence. Throughout we emphasize that most debates about cultural phylogenies can only be settled by empirical research rather than armchair speculation.
\end{abstract}

Keywords: Bayesian models, borrowing, cultural evolution, gene tree, phylogenetics, reconciliation analysis, reticulation, word tree 


\section{Two Ways of Darwinizing Culture}

The Darwinian revolution is not a stay-at-home child. All over the intellectual landscape, from medicine (Nesse and Williams 1994) to literary theory (B. Boyd in preparation; Gottschall and Wilson 2004), scholars are proudly proclaiming new approaches that are decidedly Darwinian. However, when it comes to the analysis of human social life, attempts to "Darwinize culture" have encountered a rather mixed reception. On the face of it, this is odd because Darwin himself drew heavily on analogies with cultural change to bolster his arguments for biological evolution (Mesoudi et al. 2004). For example, in The Descent of Man, Darwin (1871) noted that,

The formation of different languages and of distinct species, and the proofs that both have been developed through a gradual process, are curiously parallel. ... We find in distinct languages striking homologies due to community of descent, and analogies due to a similar process of formation. (89-90)

However, broad analogies between biological evolution and cultural change have not been sufficient to convince skeptics, such as Fracchia and Lewontin (1999), that anything of substance or utility can come of such parallels.

Current debates about Darwinizing culture typically focus on two problems with the analogies between biology and culture:

(1) Does culture have particulate units of inheritance (memes) analogous to genes?

(2) Are memes inherited with sufficient fidelity to enable cumulative selection? Again, at first glance, the fixation on memes is odd because basic Darwinian theory is agnostic about the details of inheritance. In his classic paper, The Units of Selection, Lewontin (1970) argued that any population with three features - variation, heritability, and differential fitness would evolve in a Darwinian manner. He observed that,

It is important to note a certain generality in the principles. No particular mechanism of inheritance is specified, but only a correlation in fitness between parent and offspring. The population would evolve whether the correlation between parent and offspring arose from Mendelian, cytoplasmic, or cultural inheritance. (1970: 1)

While the mechanisms of inheritance are clearly relevant to the evolvability of natural systems (Sterelny 2001, 2006a), meme-like inheritance is not a necessary requirement for descent with modification. Sterelny (2006b) argues that there are three main classes of inheritance mechanisms in adaptive cultural evolution: niche construction driving cultural group selection; vertical transmission of cultural information from organisms to their offspring; and the replication and spread of memes (which he restricts to cases where artifacts play a template role in their construction). Any one of these mechanisms will produce genealogical patterns of descent with modification. Darwin famously depicted these genealogical connections in the only figure to appear in The Origin of Species (1859) - in his drawing of a "tree of life". The same genealogical thinking that Darwin applied to biological species, he extended to human languages and cultures:

If we possessed a perfect pedigree of mankind, a genealogical arrangement of the races of man would afford the best classification of the various languages now spoken throughout the world; and if all extinct languages, and all intermediate and slowly changing dialects, were to be included, such an arrangement would be the only possible one. Yet it might be that some ancient languages had altered very little and had given rise to few new languages, whilst others had altered much owing to the spreading, isolation, and state of civilisation of the several co-descended races, and had thus given rise to many new dialects and languages. The various degrees of difference between the languages of the 
same stock, would have to be expressed by groups subordinate to groups; but the proper or even the only possible arrangement would still be genealogical; and this would be strictly natural, as it would connect together all languages, extinct and recent, by the closest affinities, and would give the filiation and origin of each tongue. (ch. 13: 422)

This suggests that there is a second way of Darwinizing culture: applying phylogenetic "tree thinking" (O'Hara 1988). Phylogenetic methods have revolutionized evolutionary biology in the last 20 years. From primatologists to protein chemists, evolutionary biologists routinely use phylogenies as the foundation of their inferences. Whilst these methods lie at the heart of evolutionary inference today (Harvey and Pagel 1991; Huelsenbeck and Rannala 1997; Pagel 1999), their application to questions of cultural evolution has been overshadowed by debates about the validity of memetics (e.g., Aunger 2000; Dennett 1995; Sterelny 2006b). However, phylogenetic methods have recently begun to be applied to questions about culture (Mace and Holden 2005). In this paper we will outline both the pleasures and perils of Darwinizing culture through the use of phylogenetic methods.

\section{The Pleasures of Phylogenies}

There are at least six fundamental questions about cultural evolution that can be answered using the power and precision of explicit phylogenetic methods.

\section{Homelands}

The search for "homelands" has provided fuel for many longstanding academic debates, and continues to be a source of enduring fascination. One particularly famous case in point is the origin of the Indo-European language family (Atkinson and Gray 2006). Since 1960 alone, there have been at least fourteen different and distinct homeland proposals, stretching from central Europe to India (Mallory 1989). There are also vigorous debates about the origins of other language families (Bellwood and Renfrew 2003). One debate that has recently witnessed a resurge of interest concerns the origin of the Uto-Aztecan language family. According to the "Northern origin" hypothesis the Uto-Aztecan homeland is in the American Southwest (Fowler 1983); by contrast, under the "Southern origin" hypothesis the homeland is in central Mexico (Hill 2001). Unfortunately, many homeland scenarios are little more than plausible narratives. A common feature of these narratives is an assertion that a particular line of evidence (archaeological, cultural or linguistic) is "consistent with" the scenario. Phylogenetic methods go beyond plausible narratives by offering a principled methodology to test homeland hypotheses: "A well-argued tree is also crucial to locating the homeland of a proto-language" (Ross 1997: 255). The most probable ancestral geographic location can be directly inferred from a phylogenetic tree by evaluating the geographic state at the root. An example of this is shown in Figure 1: Tree A shows an origin in region "a"; whereas, Tree B shows an origin in region "c". 


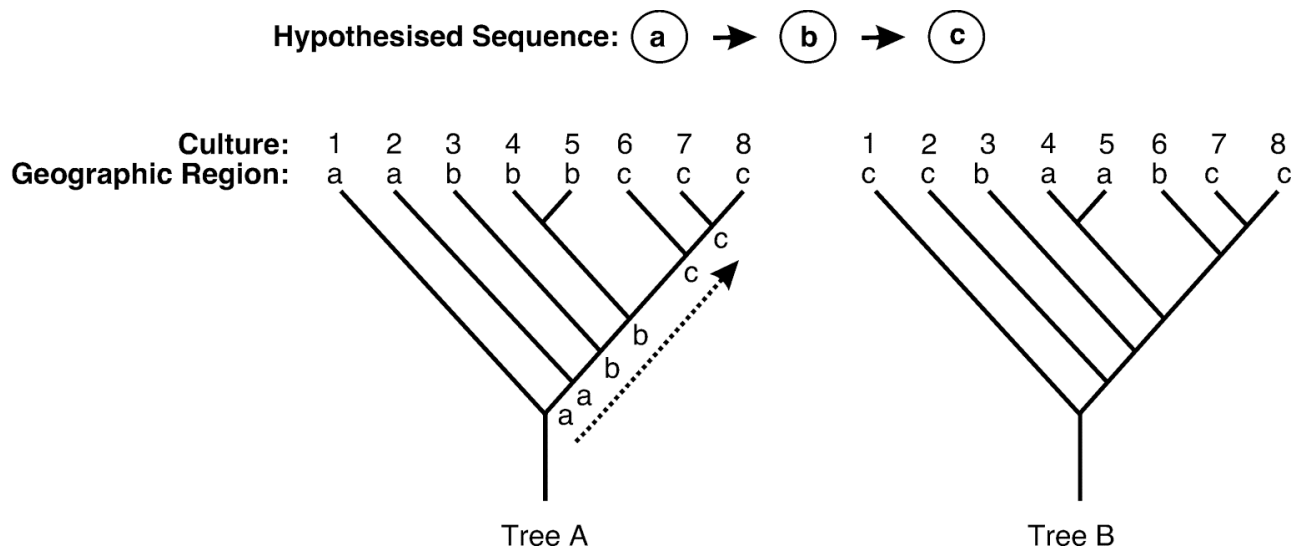

Figure 1: An example of how phylogenies can be used to test questions about geographic origin and expansion sequences. Tree A fits the proposed evolutionary sequence $a \Rightarrow b \Rightarrow c$ (dotted line) much better than tree $B$.

\section{Population expansions and sequences of cultural change}

The second type of question concerns sequences of change: in what order did cultural lineages diverge and spread? While this is closely related to questions of origin, often it is the sequence rather than the origin itself that allows us to test alternative hypotheses. Over the past several decades Bellwood and Renfrew (Bellwood 2005; Bellwood and Renfrew 2003) have argued that agricultural dispersals are the main factor that has shaped human linguistic, cultural and genetic diversity. In a recent review, Diamond and Bellwood (2003) boldly claim that the dispersal histories of fifteen major language families, including Indo-European, Uto-Aztecan, Bantu and Austonesian, are consistent with this hypothesis. For Austronesian, Diamond and Bellwood advocate an "Out of Taiwan" scenario for the origin, with a subsequent spread south and east through Indonesia, along coastal Papua New Guinea, and out into Polynesia. The concentration of nine of the ten major subgroups of Austronesian in Taiwan is consistent with this scenario (Blust 1999). In contrast, other scholars have argued for a non-agricultural origin in Indonesia with a two-pronged spread north into Taiwan and east into Polynesia (Oppenheimer and Richards 2001). Yet others have claimed that it is impossible to recover the origin of the Austronesians due to the amount of admixture between Pacific peoples and cultures (Terrell 1988; Terrell et al. 2001). We tested these competing hypotheses using phylogenetic methods to construct trees from basic vocabulary data for a sample of Austronesian languages (Gray and Jordan 2000; Greenhill and Gray 2005). We found that these language trees support the sequence of population movements proposed by the "Out of Taiwan" scenario (see Figure 2). 

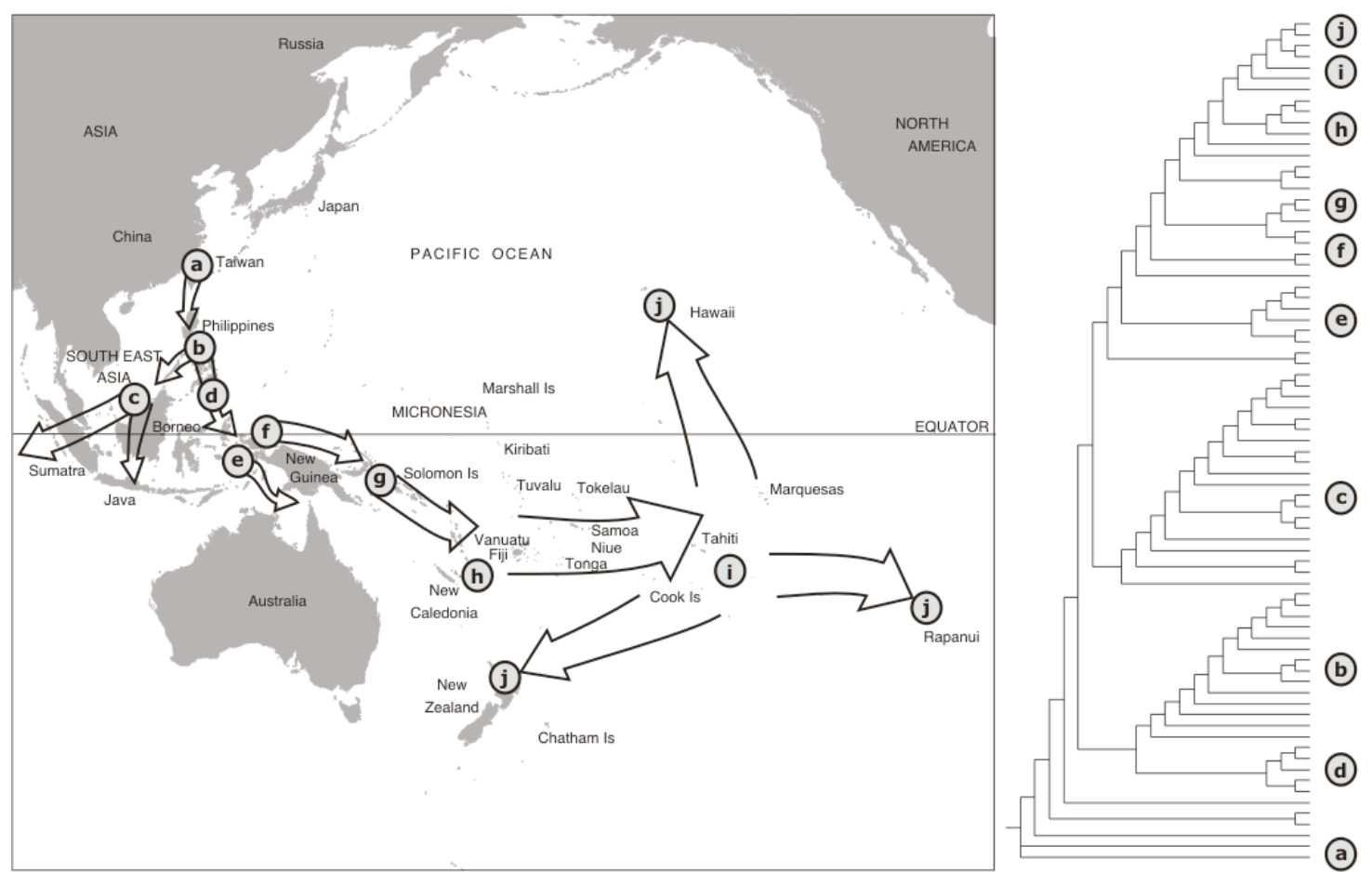

Figure 2: A map of the Pacific showing the "Out of Taiwan" scenario of Austronesian expansion, and a majority rule consensus tree concordant with this expansion scenario (adapted from Greenhill and Gray 2005).

\section{Dating divergence events}

Questions about the timing of splits have been of particular concern to linguists. During the 1950 s, Swadesh $(1952,1955)$ developed a method called glottochronology to estimate absolute dates for language divergences. However, Swadesh's method has proven to be fundamentally flawed (Campbell 2004), principally because its assumption of constant rates of lexical change can be seriously violated (Blust 2000). In contrast, phylogenetic methods are capable of reliably estimating absolute divergence dates without assuming constant rates (Sanderson 2002). This can be done by calibrating certain parts of the tree on the basis of external historical evidence from ancient manuscripts, archeology and ethno-history. Figure 3 shows an example of how phylogenetic methods can be used to estimate ages by smoothing the observed amount of change across the tree, after calibration with known historical evidence. Gray and Atkinson (2003) took advantage of the rich Indo-European historical record to study the origin of the Indo-European language family. There are two major theories of Indo-European origin - the "Kurgan expansion" hypothesis that predicts that the language family expanded at the beginning of the sixth millennium BP, and the "Anatolian farming" hypothesis that predicts that the family expanded around 8,000 to 9,500BP. Gray and Atkinson used basic vocabulary from 87 Indo-European languages to construct a Bayesian sample of language trees. Next, they calibrated branching points on the sample of trees using known historical events - such as the diversification of the Romance languages after the fall of Dacia in $112 \mathrm{AD}$ and subsequent collapse of the Roman Empire. These calibrations allowed the age of the Indo-European language family to be estimated using Sanderson's (2002) penalized-likelihood rate-smoothing method. Strikingly, the estimates for the age of the Indo-European family consistently fell within the 8,000 to 9,500 year age range predicted by the "Anatolian farming" hypothesis. Further analyses using an independent lexical dataset, and alternative models of lexical evolution, have verified these results (Atkinson and Gray 2006; Atkinson et al. 2005). 


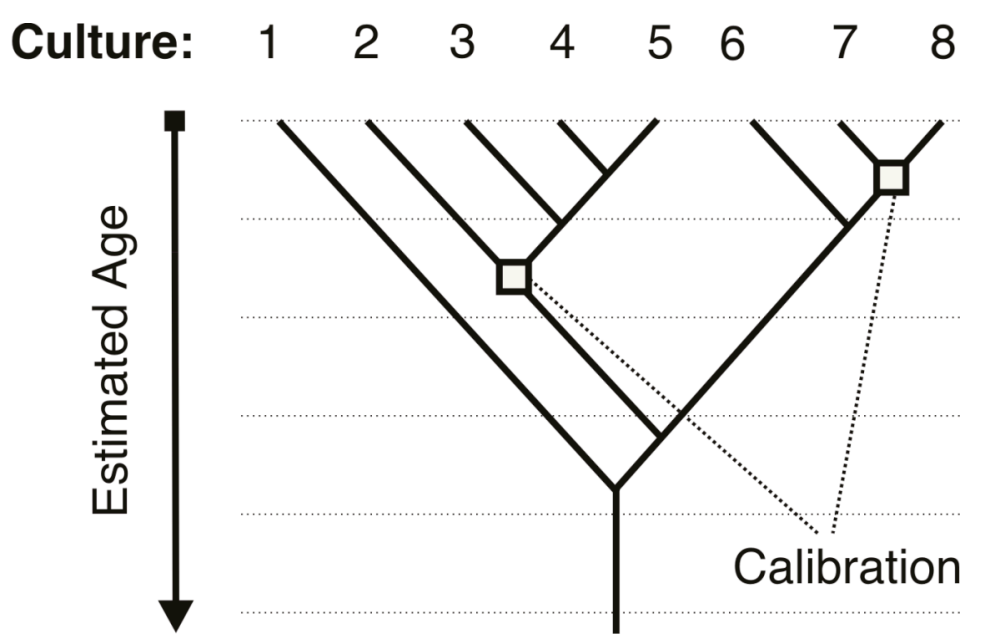

Figure 3: An example of how phylogenies can be used to estimate divergence dates. First, particular nodes are calibrated using known historical events, and then the inferred rates of change are smoothed across the tree to estimate the age of other nodes.

\section{Rates of Cultural Change}

The fourth type of question concerns rates of evolution: what factors affect rates of cultural change, and are there general and law-like principles that could account for widespread patterns in rate variation? These issues have been of particular concern to linguistics who have long noted that words with different meanings evolve at different rates (Swadesh 1952). Recently, Pagel et al. (2007) developed a powerful methodology for directly quantifying and comparing this variation. They used Bayesian phylogenetic methods to generate a sample of trees for 87 IndoEuropean languages and estimated the relative rates of evolution among core vocabulary items on those trees. They found an approximately hundred-fold difference in rates of change between the most stable vocabulary items (such as "two", "tongue", and "night") and the least stable vocabulary items (such as "dirty", "to turn", and "guts"). Next, they investigated the cause of this tremendous variation by extracting the frequency with which words are used in everyday language from large spoken-language corpora for four Indo-European languages (English, Spanish, Russian and Greek). Their analyses showed a strong positive correlation between the frequency with which a word is used today and how stable it has been over time - that is, the words people use more often change more slowly. Remarkably, by taking only the frequency of word use and the part of speech (noun, verb, etc.) into account, they were able to explain approximately $50 \%$ of the variation in the rates of evolution. This striking result demonstrates that despite all the vagaries and contingencies of 9,000 years of Indo-European history there must be some consistent mechanisms at work. Pagel et al. (2007) propose two candidate explanations for this effect: either frequently used words are perceived, recalled and produced with higher fidelity; or processes of frequency-dependent, purifying selection cause errors in frequently used words to be less likely to be adopted by a population.

Social processes can affect rates of linguistic change in other ways too. Cultural groups often use language to establish a distinct social identity by deliberately differentiating their language from its neighbors (Labov 1994). Atkinson et al. (in press) argue that if this linguistic social differentiation is occurring, there should be punctuational "bursts" of evolution shortly after languages diverge, followed by more gradual change. To test this prediction Atkinson et al. develop a Bayesian phylogenetic approach: they construct trees for basic vocabulary in IndoEuropean, Austronesian and Bantu languages; then they compare the length of the path from the tip of the tree to the root, for each language. They argue that if language evolution does not show 
punctuational bursts when languages split, then this path-length should be independent of the number of divergence events along it; however, if the formation of new languages is characterized by punctuated evolution, then this path-length should be greater for paths with more divergence events. Their analyses revealed that from $10 \%$ to $33 \%$ of the change in the three language families studied showed this punctuational pattern of evolution. This suggests a general tendency for newly emerged languages to undergo an initial burst of change - a result that is consistent with the idea that groups use language as a marker of cultural distinctiveness and intragroup cohesion.

\section{$\underline{\text { 5. Adaptation }}$}

A tremendous variety of cultural practices have been proposed as adaptations to specific environments. However, without rigorous testing adaptationist hypotheses amount to little more than suggestive "just so stories" (Gould and Lewontin 1979). Attempts to use cross-cultural data to test whether or not particular cultural traits are adaptations have frequently been confronted by what has come to be known as "Galton's problem" - the lack of statistical independence between cultures caused by their shared ancestry (Mace and Pagel 1994). Phylogenetic comparative methods can overcome this lack of independence by explicitly estimating gains and losses of traits on the phylogeny. Figure 4 shows a pattern that might be expected if a trait evolves as an adaptation to the presence of another trait. Phylogenetic comparative methods can evaluate whether a given trait tends to lead to the evolution of another trait, or vice versa. Cross-cultural data have suggested that there is a coevolutionary relationship between cattle farming and patrilineal patterns of inheritance (Aberle 1961); however, due to Galton's problem, it is difficult to infer whether this is the result of shared history or an adaptation. In a series of elegant studies, Holden and Mace $(2003,2005)$ provided evidence that, in Bantu cultures at least, "the cow is the enemy of matriliny". First, under a likelihood framework, they used basic vocabulary from 68 Bantu languages to generate a sample of language trees. Second, they used anthropological data to code each of these 68 languages as either patrilineal or matrineal, and either cattle keeping or non-cattle keeping. And third, they used likelihood-based comparative methods (Pagel 1994) to test the coevolutionary relationships between these traits on the sample of language trees. They found that (a) when non-cattle keeping populations acquired cattle they usually switched to patriliny, and that (b) cattle-keeping populations were very unlikely to become matrilineal.

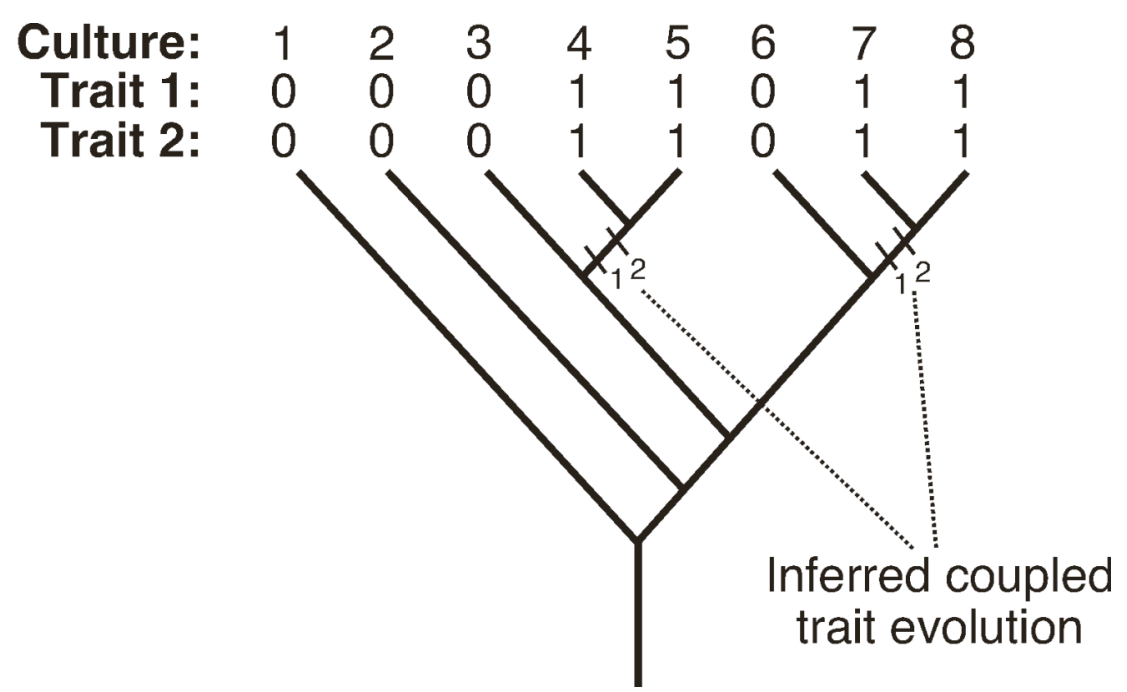

Figure 4: An example of coupled character evolution on a phylogeny. The presence or absence of Trait 1 and Trait 2 are shown by a binary coding on the tips of the tree (0: Absent, 1: Present). Character changes in Trait 1 and Trait 2 occur twice, each time on the same branch. 


\section{Ancestral States}

Anthropologists and linguists are often interested in making inferences about the characteristics of parent cultural groups. To answer questions about ancestral states, or proto-forms, of languages and cultures, scholars have traditionally relied on a "widespread equals ancestral" (or "majority rules") heuristic: if a trait is widespread in daughter communities, then the parent most likely had it too (Campbell 2004). However, this heuristic can easily lead to error. Figure 5 shows an example where the ancestral state of the trait is "a", despite the fact that the state "b" is more widespread. This example clearly illustrates the importance of taking phylogeny into account when making inferences about ancestral states. In a pioneering study, Kirch and Green (2001) took an explicitly phylogenetic approach to reconstructing the characteristics of ancestral Polynesian society. Following Marck (1996), they argued that if a trait is present in extant cultures from both Western Polynesia (in particular Tonga because it is widely accepted as the first lineage to split off at the base of the Polynesian language tree) and Eastern Polynesia, then that trait could be inferred as present in ancestral Polynesia. For example, by demonstrating that languages in both Eastern Polynesia and Tonga have a word descended from the ancestral form, $* f(a, 0) u l u a$, for double-hulled canoes, they inferred the presence of double-hulled canoes in ancestral Polynesia. The phylogenetic reasoning exemplified in the work of Kirch and Green (2001) can be made even more precise by the use of Bayesian phylogenetic methods, which can infer ancestral states in a way that controls for Galton's problem and uncertainty in tree topology (Pagel et al. 2004). Recently, Fortunato et al. (2006) have used Bayesian phylogenetic methods to estimate ancestral states of marriage transfer in Indo-European societies. Earlier studies using non-phylogenetic methods had concluded that a system of bridewealth evolved before dowry (Jackson and Romney 1973). Fortunato et al. tested this hypothesis by mapping the presence of dowry or bridewealth onto a distribution of Indo-European language trees. Contrary to previous work, their results showed that, despite bridewealth being more prevalent in extant cultures, dowry was more likely to have been the ancestral state. Furthermore, they used their phylogenetic trees to make some specific inferences, such as that bridewealth probably evolved at least four times.

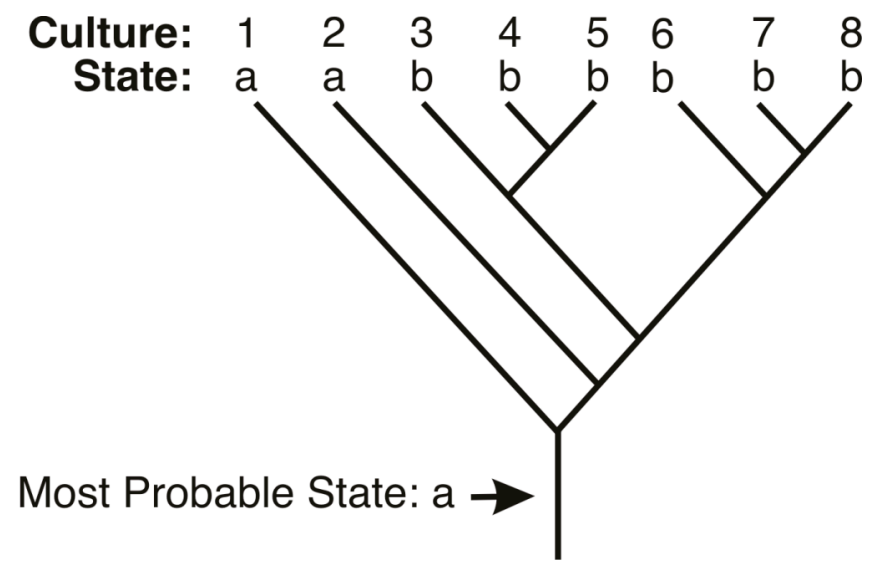

Figure 5: An example of why it is important to take phylogenetic history into account when reconstructing ancestral states. State " $b$ " is more widespread than state " $a$ ", but state " $a$ " is present in the basal lineages 1 and 2. Therefore, state " $a$ " would be the most likely ancestral state under most models of character state change. A "majority rules" heuristic would lead to the incorrect inference that " $b$ " was the ancestral state. 


\section{The Perils of Cultural Phylogenetics}

The alleged perils of Darwinizing culture with phylogenies have been widely trumpeted. Perhaps the most vocal critic of Darwinian approaches to culture has been the eminent palaeontologist Stephen Jay Gould. In his 1987 book, An Urchin in the Storm, he proclaimed that:

Human cultural evolution proceeds along paths outstandingly different from the ways of genetic change... Biological evolution is constantly diverging; once lineages become separate, they cannot amalgamate (except in producing new species by hybridization- $\mathrm{a}$ process that occurs very rarely in animals). Trees are correct topologies of biological evolution... In human cultural evolution, on the other hand, transmission and anastomosis are rampant. Five minutes with a wheel, a snowshoe, a bobbin, or a bow and arrow may allow an artisan of one culture to capture a major achievement of another. (1987: 70)

Gould has reiterated this argument in numerous subsequent publications. For example:

The basic topologies of biological and cultural change are completely different. Biological evolution is a system of constant divergence without subsequent joining of branches. Lineages, once distinct, are separate forever. In human history, transmission across lineages is, perhaps, the major source of cultural change. (1991: 64)

Gould seems to have believed that while phylogenetic methods are great in the biological realm, in studies of cultural evolution they are doomed to failure because cultural change is governed by completely different principles. Other critics have voiced similar concerns. We have identified at least five ways that merging of lineages has been claimed to invalidate a phylogenetic approach to culture. In this section we examine these five perils.

\section{Faulty Analogy?}

Perhaps the most frequently voiced criticism of cultural phylogenetics is that it rests on a false analogy: biological evolution is treelike, but in culture reticulation rules (Bateman et al. 1990; Borgerhoff Mulder 2001; Borgerhoff Mulder et al. 2006; Moore 1994). Reticulation occurs at a range of levels in cultural evolution (see table 1). At the lowest level is the borrowing of small, discrete aspects of culture. For example, the English language has borrowed the word taboo from Tongan (Oxford English Dictionary 2000), but this lexical borrowing is not coupled with other linguistic or cultural traits, and it has had little or no effect on any other aspect of the recipient language or culture. A step up from discrete traits is the borrowing of cultural complexes or clusters - aspects of culture that are functionally linked or correlated. An example of a functionally linked cultural complex is the Kava drinking ceremony found in many Oceanic cultures. The Kava (Piper methysticum) root requires preparation to make it drinkable, and this drink is associated with a number of drinking rituals and traditions. This "Kava complex" appears to have been borrowed as a whole from Polynesia into Micronesia, with subsequent differentiation of some components (Crowley 1994; Lynch 2002). Non-functionally linked aspects of culture can also show a propensity to be transmitted together. For example, in variants of the fairytale Little Red Riding Hood, the main character typically exhibits a cluster of attributes: young, female and wearing a red cape. Superficially at least, none of these attributes are essentially linked to one another, yet they all tend to co-occur. (However, we note that literary theorists have developed some rather colorful attempts to establish functional links between Little Red Riding Hood's attributes; e.g., Dundes 1989 and Zipes 2006.) 


\begin{tabular}{|l|l|l|}
\hline Level & Culture & Biology \\
\hline discrete elements & Single words (“taboo") & $\begin{array}{l}\text { Meiosis } \\
\text { Horizontal Gene Transfer (Dagan } \\
\text { and Martin 2006) }\end{array}$ \\
\hline character groups & $\begin{array}{l}\text { Complexes (Kava) } \\
\text { Clusters (Little Red Riding Hood) }\end{array}$ & $\begin{array}{l}\text { Symbiosis (e.g. Poole and Penny } \\
\text { 2007) }\end{array}$ \\
\hline population lineages & $\begin{array}{l}\text { Creolization (Takia) } \\
\text { Mixed Languages (Michif) } \\
\text { Religious Syncretism (Umbanda) }\end{array}$ & Hybridization (Mallet 2002) \\
\hline
\end{tabular}

Table 1: Parallels between biological and cultural evolution in the patterns of reticulation. In both cases reticulation can occur at the level of discrete elements, at the level of character groups, or between population lineages.

Moving even further up the hierarchy, the blending of cultural lineages can also occur at the population level. Linguists have extensively studied different patterns of blending between language lineages (Thomason and Kaufman 1988). The partial blending of language lineages has occured on the island of Karkar, near Madang in Papua New Guinea. One half of the island is occupied by people who speak the Austonesian language Takia; while the other half is occupied by people who speak the Papuan language Waskia. Takia shows an interesting pattern of borrowing from Waskia - it has adopted grammatical features from Waskia, such as verb-final clause marking; yet the majority of the lexicon remains Austronesian (Ross 1996). In other cases of contact between languages the blending of two lineages can be much more complete. An interesting example of this can be seen in Michif, a "mixed" language spoken in Canada that arose from the interaction between French-Canadian trappers and Cree-speaking Native Americans. Michif is the outcome of a complex intertwining of lexicon and grammar from both French and Cree (Bakker 1997; McWhorter 2001). Anthropologists have also documented cases of cultural hybridization, such as religious syncretism. For example, African slaves taken to Brazil were frequently forbidden from practising their native religions. However, many slaves translated and reinterpreted ideas and deities of their native religions into the language of Catholicism. This created new hybrid religions, such as Umbanda, which gave Catholic saints dual identities as Catholic saints and African deities (Brown and Bick 1987).

Clearly reticulation is rampant in cultural evolution. However, the Gouldian argument that cultural evolution is inherently more reticulate than biological evolution is biologically naïve reticulation can occur at many different degrees and levels in the biological hierarchy. At the lowest level, is the recombination of genes during meiosis and the horizontal transfer of genes between different species. Horizontal gene transfer has played a major role in the development of the bacterial genome (Dagan and Martin 2006), and still plays an active role in, among other things, the development of antibiotic resistance and pathogenicity (Boucher et al. 2003). This has occurred as the result of both the transfer of complex gene clusters and the widespread transfer of single genes. A recent analysis of 190 prokaryotic genomes suggests that horizontal gene transfer has affected at least two-thirds of over 57,000 gene families (Dagan and Martin 2007). This process is not just confined to bacteria; recent studies have also shown horizontal transfer of genetic information between bacteria and eukaryote genomes (Dunning Hotopp et al. 2007). Further up the biological hierarchy, possibly corresponding to the exchange of cultural complexes and clusters, is the much-debated origin of the mitochondria in eukaryotes. Current data suggest 
that mitochondria became engulfed by eukaryotes soon after their divergence from prokaryotes (Poole and Penny 2006). At the level of population lineages, reticulation is seen in hybridization, where two different species exchange genetic material and create viable offspring. Hybridization is often regarded as rare and "unnatural", but a recent survey showed natural interspecific hybridization in at least $10 \%$ of the animal, and $25 \%$ of the plant species reviewed (Mallet 2005).

In summary, far from there being a striking disanalogy between biological and cultural evolution, these examples actually show that there are strong similarities between biological and cultural reticulation (see table 1).

\section{Methodological Straitjacket?}

At a recent symposium on phylogenetic methods in archaeology, one long-term phyloskeptic barked, "This is not history! This is history put into nested boxes!" The skeptic had a valid point: standard phylogenetic programs assume that a tree is the appropriate structure to fit; these programs will output trees even when the data are highly non-treelike. In such cases, clumsy mechanical applications of phylogenetic methods are likely to generate meaningless results. However, with more sophisticated use, the methodological straightjacket imposed by phylogenetic methods need not be as tight as some critics have supposed. While it is true that standard phylogenetic programs always output a tree (or trees), it is possible to evaluate how well the data actually fit the tree model. This approach was taken by Collard et al. (2006) who compared 21 biological and 21 cultural datasets using two measures of character fit (the consistency index and the retention index). They interpret their analyses as providing no evidence that cultural data fit a tree model less well than biological data. However, a limitation of their study is that the indices they used do not identify the causes of poorly fitting characters. Fortunately, as we discuss next, significantly more informative methods have been developed.

Phylogenetic trees themselves can be used as a starting point to investigate processes that have produced the non-treelike signal in the data. An elegant analysis of this type can be seen in Faith's (1989) paper entitled, Homoplasy as Pattern. In this paper Faith explored patterns of non-treelike signal in an osteological dataset for Anseriforme birds. He first removed all the phylogenetically informative characters, and then used a multidimensional scaling analysis on the remaining characters. This analysis grouped the birds by habitat, which suggested that convergent evolution driven by foraging mode had shaped these characters. More recently, Lester et al. (2005) have used phylogenetic methods to study the evolution of the eukaryotic genome. By inferring the date that specific genes first appeared in prokaryote phylogenies, they were able to test the hypothesis that the eukaryote genome arose from successive horizontal transfer events. Their results support the hypothesis that the eukaryote genome is a mosaic of multiple horizontal gene transfers from prokaryotes. These studies illustrate that, when carefully used, phylogenetic methods actually provide ways of making inferences about reticulation.

Recently, methods have been developed that do not assume a tree, but instead construct networks (Huson and Bryant 2006). The NeighborNet method developed by Bryant and Moulton (2002) provides a particularly useful way of visualising the extent of non-treelike signal in a dataset prior to (or instead of) constructing trees. Bryant et al. (2005) used this approach to investigate the degree of conflicting signal in Indo-European basic vocabulary. Although they found that, overall, the data were strongly treelike, some regions of the NeighborNet showed considerable conflict. Figure 6 shows a NeighborNet for a subset of Germanic languages with considerable conflicting signal for the position of Sranan. This is exactly what would be expected given that Sranan is a creole developed by African slaves in Surinam on the northern coast of South America. The English established Surinam in 1651 as a slave colony, but Dutch had been the 
official language since 1667 (McWhorter 2001). The basic vocabulary reflects this hybridization and produces a boxlike structure indicating conflicting signal in the NeighborNet.

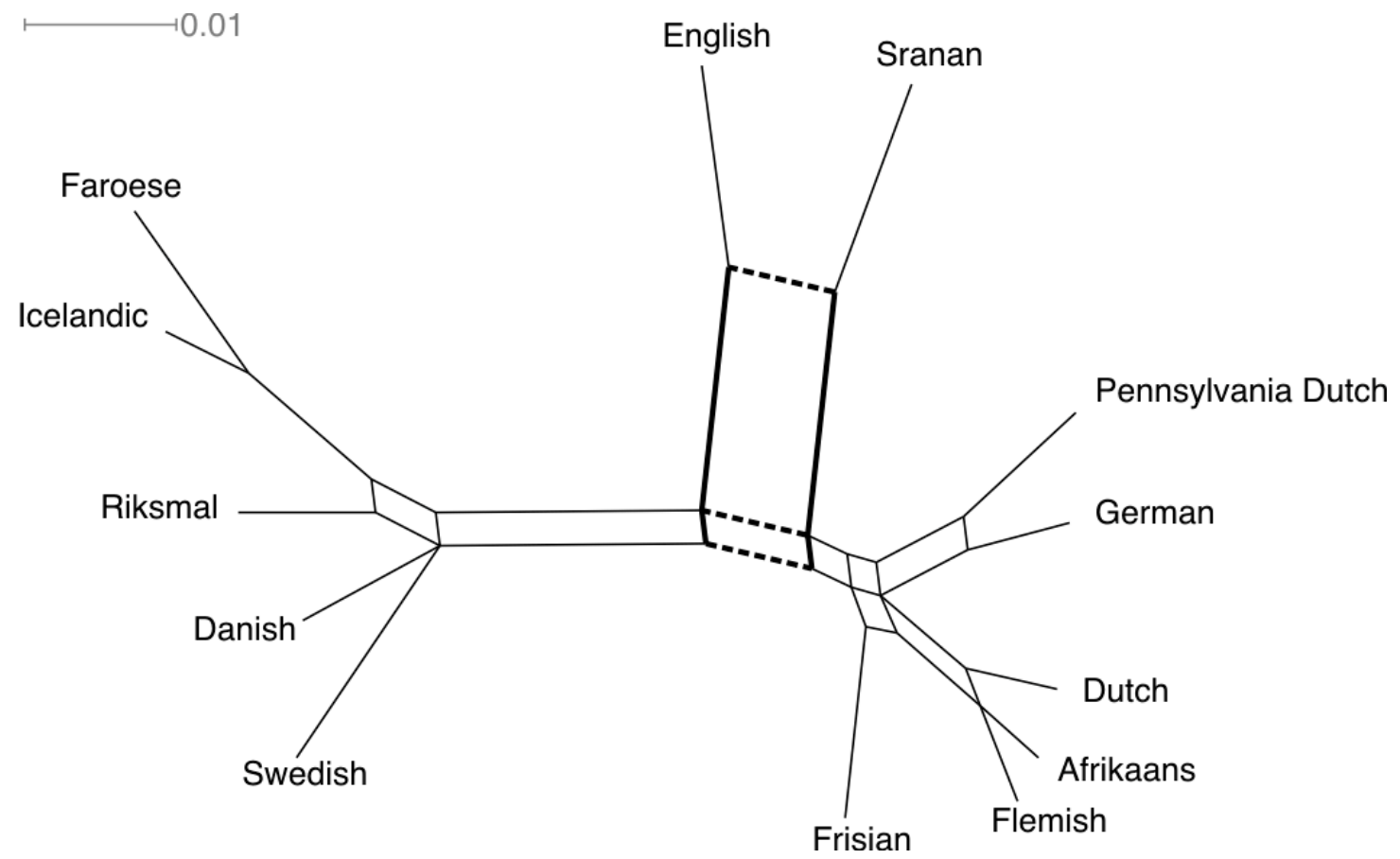

Figure 6: A NeighborNet derived from basic vocabulary data showing conflicting signal in a set of Germanic languages. The bold lines represent the signal grouping English with the creole Sranan, while the dotted lines represent the signal grouping Sranan with Dutch and other Western Germanic languages. The length of the lines are proportional to the strength of lexical support for that grouping.

\section{Are Cultures Species?}

Some proponents of phylogenetic approaches to cultural evolution defend the view that cultures are relatively discrete, bounded, integrated groups analogous to vertebrate species (e.g., Mace and Holden 2005). Considerable skepticism has been expressed about this view by anthropologists who are otherwise sympathetic to evolutionary views of culture, but are unimpressed by the merits of cultural phylogenies. In an important paper, R. Boyd et al. (1997) ask, "Are cultural phylogenies possible?" They point out that a range of positions are possible on the question of how integrated cultural histories are, and outline four positions along a continuum of cohesion: (1) cultures as tightly integrated; (2) cultures as containing core traditions that are tightly linked and vertically transmitted, with peripheral aspects that are less cohesive and marked by frequent borrowing; (3) cultures as containing some aspects that are bound together, but no core traditions; and (4) cultures as collections of ephemeral entities. At this point, two things need to be stressed. First, just as the use of phylogenetic methods does not require a commitment to the view that evolution is totally treelike, so the construction of phylogenies for aspects of culture does not require a commitment to the view that cultures are as discrete and cohesive as vertebrate species. Second, the question about the extent of cultural cohesion is not one for armchair speculation - it is an empirical issue that should be answered on a case by case basis.

One way in which the debate about the extent to which cultures act as cohesive evolutionary units might advance is by building further on biological analogies. Evolutionary biologists routinely 
construct trees based on DNA sequences. We all know that "every gene has its own history" and yet trees for different genes generally produce similar phylogenies that reflect their joint evolutionary history. However, gene trees are not always congruent with species trees (Fitch 1970; Maddison 1997). Figure 7 shows how incongruent gene genealogies can arise: Tree A shows different gene lineages within a single species tree; Tree B shows processes that can occur within one gene lineage such as gene duplication, lineage sorting, and horizontal gene transfer; and Tree $\mathrm{C}$ shows how these processes can cause incongruence between the gene tree and the species tree. Biologists have developed methods for "reconciling" these incongruent histories that capture the complexity of the joint evolutionary history of different genes (Charleston 2003; Page and Charleston 1998). We suggest that the same approach could be productively applied to the evolution of cultural traits. Figure 8 shows a real example of reconciling the incongruence between word trees and language trees in a number of Indo-European languages: Tree A shows the history of the word "three", which has a clear pattern of vertical descent; Tree B shows the borrowing of the word "animal" from French into English, with the subsequent sorting of the existing Germanic form; and Tree $\mathrm{C}$ shows a reconciled history for both of these word lineages within the language tree, which requires one historical transfer and two extinction events to reconcile these word trees. 


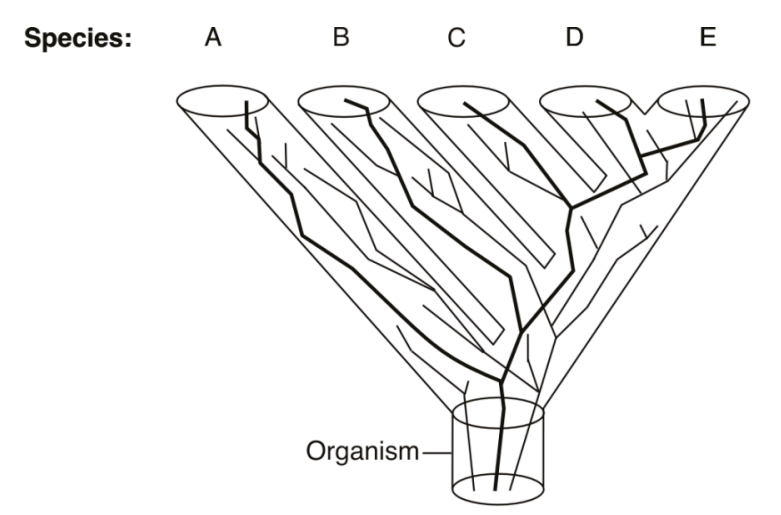

Tree A

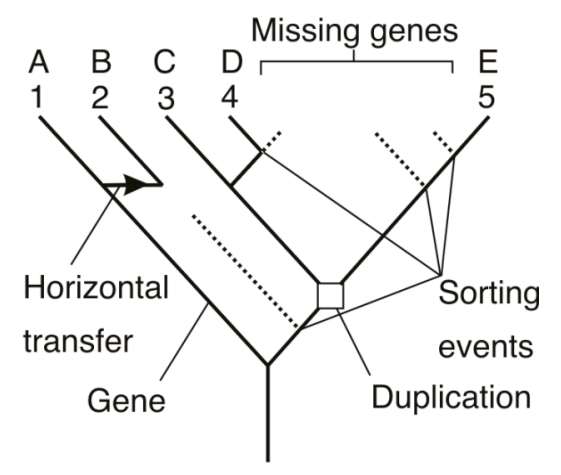

Tree B

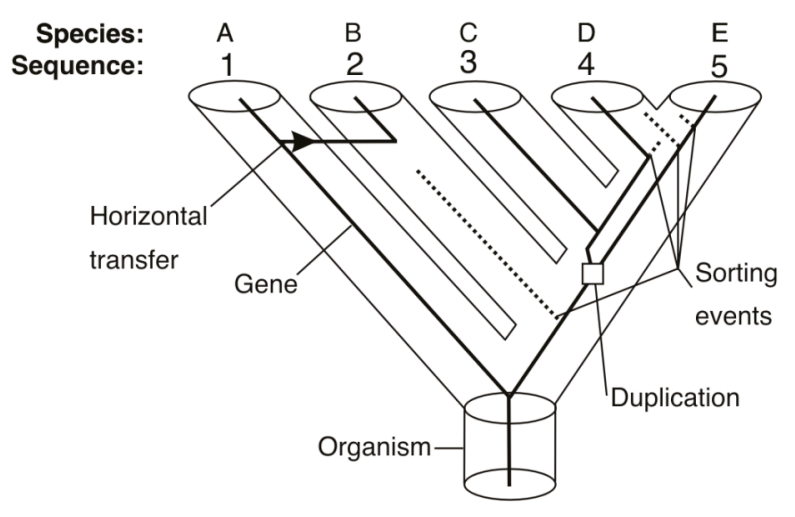

Tree C

Figure 7: An example of how incongruent gene trees can arise and the inferences required to reconcile their incongruent histories. Tree A shows the evolution of gene lineages (the thin lines) nested in a species tree (the tubular tree of species $A, B, C, D$ and $E$ ). Tree $B$ shows how gene duplication, lineage sorting and horizontal transfer events can produce a gene tree that is incongruent with the species tree; for example, the gene sequence 4 found in species $D$ is most closely related to sequence 3 in species $C$, even though species $D$ is more closely related to species $E$ than it is to species $C$. Tree $C$ shows how the incongruent gene tree can be reconciled with the species phylogeny by postulating one gene duplication, four sorting events, and one horizontal transfer (adapted from Page and Charleston 1998). 


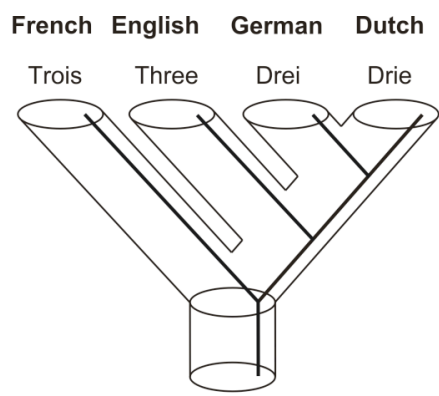

Tree A

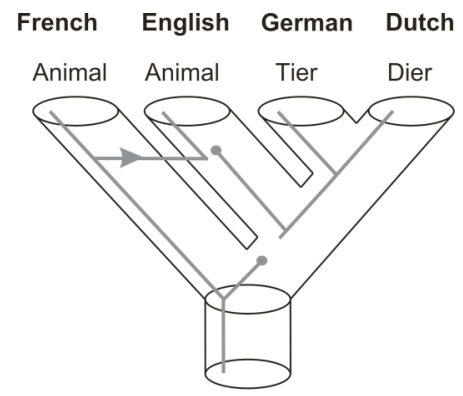

Tree B

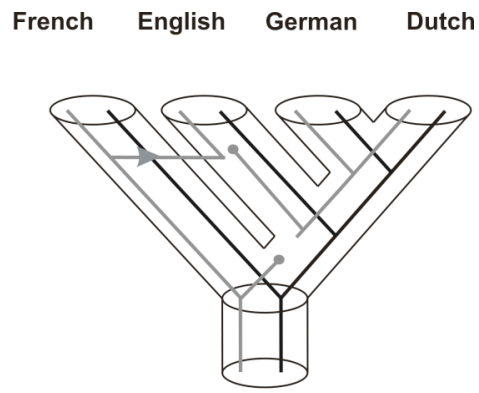

Tree C

Figure 8: An example of reconciliation analysis showing two Indo-European word lineages nested in a language tree. Tree A shows the history of words for "three". Tree B shows the history of words for "animal". Tree A is congruent with the language phylogeny whereas Tree B is incongruent because of borrowing from French into English. Tree C shows the reconciled history of both word lineages inside the language tree. This coevolutionary history postulates one horizontal transfer and two sorting events.

\section{Estimation Errors?}

The next potential peril concerns the trees themselves. One could believe that reticulation was far from the dominant force in cultural evolution, yet still maintain that trees of cultural traits will be all bent out of shape by even quite small amounts of horizontal transmission. The topologies, ancestral state reconstructions, and date estimates could thus all be well off the mark. However, at least in the case of language trees, this seems unlikely: language trees that have been constructed from basic vocabulary using phylogenetic methods for three major language families (Gray and Atkinson 2003; Gray and Jordan 2000; Holden 2002) are broadly congruent with classifications proposed by linguists on the basis of phonological and grammatical evidence. We suspect that some phyloskeptics may remain unconvinced by the congruent trees produced from different datasets by different methods: perhaps horizontal diffusions have caused them all to converge on inaccurate trees.

We advocate two approaches for assessing the accuracy and robustness of phylogenetic inferences in a principled manner: (1) by assessing their ability to reconstruct known cultural histories; and (2) by directly manipulating horizontal transfer using simulation studies. Frustratingly, despite numerous reviews and edited books on the subject of cultural phylogenies (e.g Borgerhoff Mulder et al. 2006; Collard et al. 2006a; Forster and Renfrew 2006; Lipo et al. 2006; Mace and Holden 2005; Mace et al. 2005), there have been relatively few of either of these kinds of studies.

In a recent study, Tëmkin and Eldredge (2007) have come close to the kind of historically informed analysis we advocate. They used a combination of tree- and network-based phylogenetic methods and historical evidence to analyze the history of the brasswind cornet. Their analysis demonstrated that a simple parsimony tree is not a good fit to the known history of these instruments. Instead, they argue that the best summary for the history of cornets contains 23 lineage splits and 11 horizontal transfers. The authors interpret their study as a demonstration of the limitations of phylogenetic analyses of culture. However, we think that their study provides little evidence for their pessimistic conclusion since it is far from clear that the technological change of brasswind cornets during the period from 1825 to 2004 provides a good general model of cultural evolution. First, many of the changes they document are consistent with serial replacement rather than splitting of lineages. Second, other cultural traits might evolve quite differently; for example, many of the traits of most interest to anthropologists involve codified 
practices and ancient rituals with tighter intergenerational constraints that are likely to limit the impact of horizontal transfer. We reiterate that such issues will not be resolved by armchair speculation. We will only begin to get answers to these questions after studying diverse cultural phenomena.

The ideal way to determine whether phylogenetic methods perform well on cultural data is to compare the results of analyses to cultural traits with known histories. Spencer et al. (2004) have made a start along these lines. They created an artificial manuscript tradition by having 20 volunteer "scribes" copy different versions of a manuscript (some copied the original, others copied scribal copies). They then applied phylogenetic methods and found that they recovered much of the true history. However, they did not investigate the effect of hybridization something that is known to occur in real scribal traditions. For example, when translating the New Testament from Greek and Latin into other languages, Christian scribes frequently worked from multiple manuscripts in order to choose the readings they deemed most appropriate (Ehrman 2005). To investigate the ability of phylogenetic methods to recover the true phylogeny in cases with known horizontal transmission, we have begun to analyze the phylogeny of football (Sullman and Gray unpublished manuscript). Figure 9 shows our preliminary results: Tree A shows the known history of football-type sports, and Tree B shows a phylogeny constructed from traits such as the presence or absence of scrums and fullbacks. The estimated tree is more similar to the true tree than would be expected by chance (as measured by the quartets distance Day 1986). However, the estimated tree does contain a few striking departures. Canadian Football is historically derived from the ancestor of rugby, but today closely resembles the American versions of the game. In this branch of the tree geography has trumped deeper phylogenetic history. On the basis of these few studies of known human cultural phylogenies it is simply too early to make broad generalizations, or to draw any firm conclusions about the extent to which phylogenetic estimates will be biased by the horizontal flow of information.

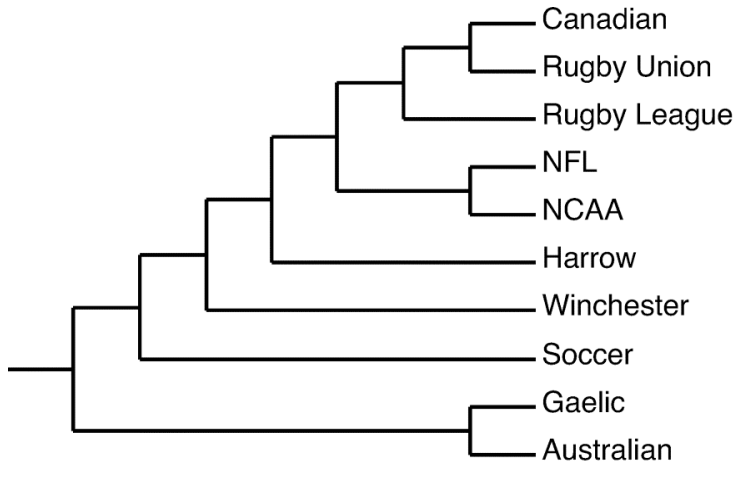

Tree A: Known Phylogeny

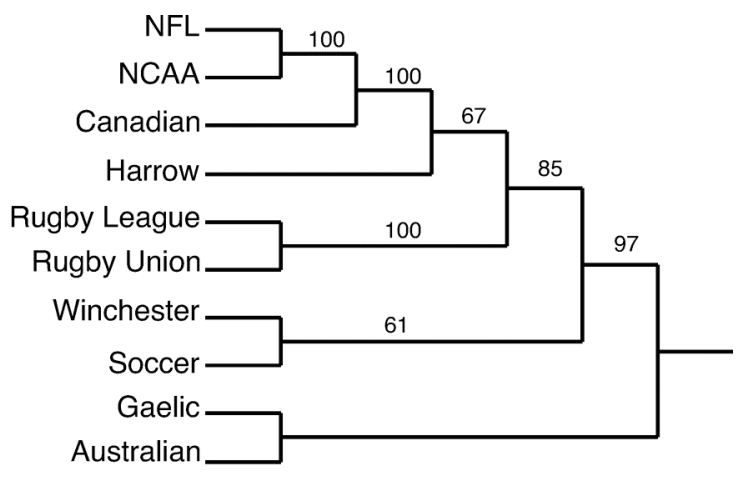

Tree B: Inferred Phylogeny

Figure 9: A phylogeny of different versions of football. The known phylogeny A differs from the inferred phylogeny $B$ in a number of ways. The major difference is caused by aspects of American football diffusing into Canadian football. Values on the branches show bootstrap support for each node, with $>90$ considered strong support and $<75$ considered weak.

The results from recent simulations of horizontal transmission present a similarly mixed picture. There are many ways horizontal transmission could be simulated. It could be simulated at a constant rate through time or be concentrated in temporal pulses. It could be spread randomly across the tree or restricted to a subset of the cultures. Intermediate scenarios are also possible where the probability of horizontal transmission decreases as the cultures diverge either in space 
or time. Atkinson et al. (2005) simulated the effects of borrowing on the estimation of divergence dates for Indo-European languages. They found that under both localized and widespread borrowing estimates for the age of the root in the simulated trees were relatively robust. Only very high levels of borrowing ( $>20 \%$ of the traits every 1000 years) produced substantial underestimates of the root age for the language family. In contrast, McMahon and McMahon (2005) report results from an Excel spreadsheet simulation in which language tree topologies were substantially perturbed by $20 \%$ borrowing between two languages in the last 20 of 220 generations. It is difficult to reconcile these two apparently contradictory findings because there are numerous differences between the simulations. The phylogenetic parameters being estimated were different (time depth vs. topology), as were the borrowing scenarios (global and localized vs. pairwise), and the methods of tree construction (Bayesian phylogenetics vs. Neighbour Joining). We are further exploring these issues in a series of simulations (Greenhill et al. unpublished manuscript). Our results suggest that both tree topology and time depth estimates obtained using Bayesian phylogenetic methods are quite robust to the effects of borrowing, with topology being more robust than time depth.

A less rosy picture of the effect of horizontal transmission has been painted by Nunn et al. (2006), who simulated the evolution of continuous and discrete characters in a spatial framework. They claim that their results demonstrate that horizontal transmission can produce substantively misleading inferences about trait co-evolution. However, we think that such pessimism is unwarranted because the levels of extinction and horizontal transmission used in their study were unrealistically high.

In summary, while strong prejudices about the impact of horizontal transmission on phylogenetic analysis abound, a great deal more work needs to be done before it will be possible to make accurate generalizations about the conditions under which phylogenetic studies fail to provide accurate and robust results.

\section{Is Language Unique?}

There is a conspicuous feature in the examples we have discussed above. Most of the phylogenies pertain to one particular aspect of culture: language. This does not reflect some idiosyncratic bias on our part, but rather the lack of non-linguistic cultural data suitable for phylogenetic analysis. There are at least three reasons for this. First, in historical linguistics there is an established and sophisticated tradition of comparative analysis across languages (Durie and Ross 1996). This tradition has generated a wealth of data that is ideally suited for phylogenetic analysis. For example, we have taken advantage of the copious amounts of data recorded on Austronesian basic vocabulary to develop a database of over 100,000 lexical items from over 500 Austronesian languages (Greenhill et al. 2003-2007). In marked contrast, comparative ethnography has been unfashionable in anthropology for quite some time. Kirch and Green (2001) lay much of the blame on postmodern critics of anthropology (e.g., Clifford and Marcus 1986) who, among other things, tend to be deeply suspicious of any attempt to make objective comparisons between cultures. Second, although some large cross-cultural datasets do exist they frequently have characteristics that unfortunately limit their usefulness for phylogenetic analysis. Murdock's (1967) Ethnographic Atlas is an excellent case in point; although it contains a wealth of crosscultural data, the sampling method he employed means that it lacks information about closely related cultures - the very information that is most useful in phylogenetic analysis. Finally, language is readily divided into distinct units (such as words, phonemes and grammar) that render linguistic data readily amenable to phylogenetic analysis. By contrast, it is not immediately clear what the appropriate units of analysis would be for many other aspects of culture. 
Kim Sterelny (personal communication) has suggested that language might be more stable and coherent than other aspects of culture. We think that there are some plausible reasons why this might be true. First, early in development, children tend to learn language from their parents, and this enforced vertical transmission tends to maintain inter-generational consistency (Labov 2007). Second, language change is strongly constrained by the need to communicate with others. English, for example, is often seen as in dire need of improvement; numerous suggestions for how this could be done have been raised by people like Mark Twain and Benjamin Franklin. In a letter to a friend, Franklin proposed to reform English by removing various unnecessary letters like "c" and "y". The friend's response suggested that there would be "meni inkanviiniensis az vel az difikylties" (Bragg 2003). So, whilst languages do change rapidly, they can't change completely overnight. In contrast, other aspects of culture might not have such tight intergenerational and communicative stabilizing constraints; as Gould noted, all it takes is five minutes with a bobbin or a bow and arrow for cultural transmission to occur. In short, there can be cultural, but not linguistic, revolutions. While these arguments are plausible, we maintain that the extent to which linguistic evolution is unique is an issue that is best addressed empirically, rather than through armchair speculation. Recently phylogenetic methods have begun to be applied to such topics as weaving motifs in Turkmen carpets (Collard and Tehrani 2005), basketry traditions in Northern California (Jordan and Shennan 2003, 2005) and Paleoindian projectile points (Darwent and O'Brien 2006). Only when more studies like these have been completed will we be in a position to answer Sterelny.

\section{A way forward}

We believe that the current highly polarized debates about the shape and fabric of human history are not particularly productive. Phylophiles and their rhizomatic critics risk reviewing the field to a standstill. The way forward is not to be found by charging onward building trees in a blinkered and unreflective fashion, nor by hand-waving about the perils of cultural phylogenies. The perils are real, if sometimes overstated. However, simply giving up at the first sign of a horizontal transmission or an incongruent tree is no solution either. Instead we believe that progress can be achieved by a combination of conceptual reframing, new methodology, and empirical research. We shall discuss each of these in turn.

The debate over cultural phylogenetics, like many polarized debates, is better conceptualized as involving positions along continuous dimensions than dichotomous camps. In a fascinating paper Darwinian Populations and Transitions in Individuality, Godfrey-Smith (in press), has outlined a dimensional framework for conceptualizing evolutionary transitions. Instead of asking "which populations are Darwinian and which are not?", he positions different kinds of populations on a state space with three dimensions: $H$, the fidelity of inheritance; $S$, the extent to which difference in realized fitness depends on intrinsic characters; and $C$, the smoothness of the fitness landscape. We think a similar dimensional approach could be productively applied to the study of cultural evolution. Instead of a priori debates about whether culture evolves, or if cultural phylogenies are possible, we should be asking where particular aspects of cultural lie on at least three dimensions.

The first dimension we propose is $R_{v}$, the rate of change in characters transmitted vertically between generations. If this rate is very slow relative to the time period being studied then there will be too little character change to allow the construction of cultural phylogenies. If $R_{v}$ is too fast then the trace left by "descent with modification" will be erased. The second dimension is $\mathrm{R}_{\mathrm{h}}$, the rate of horizontal transmission. At low rates of $R_{h}$ the estimated phylogenies will be good estimates of the cultural history. At high rates of $\mathrm{R}_{h}$ the estimated phylogenies will become increasingly inaccurate and poor summaries of the overall history. The third dimension is $\mathrm{C}$, a 
measure of the extent to which different aspects of culture are coupled together. This dimension could be thought of as analogous to linkage in genetic inheritance. At high values of $\mathrm{C}$ cultural lineages will cohere together like vertebrate lineages, while at low values they will form only transitory clusters.

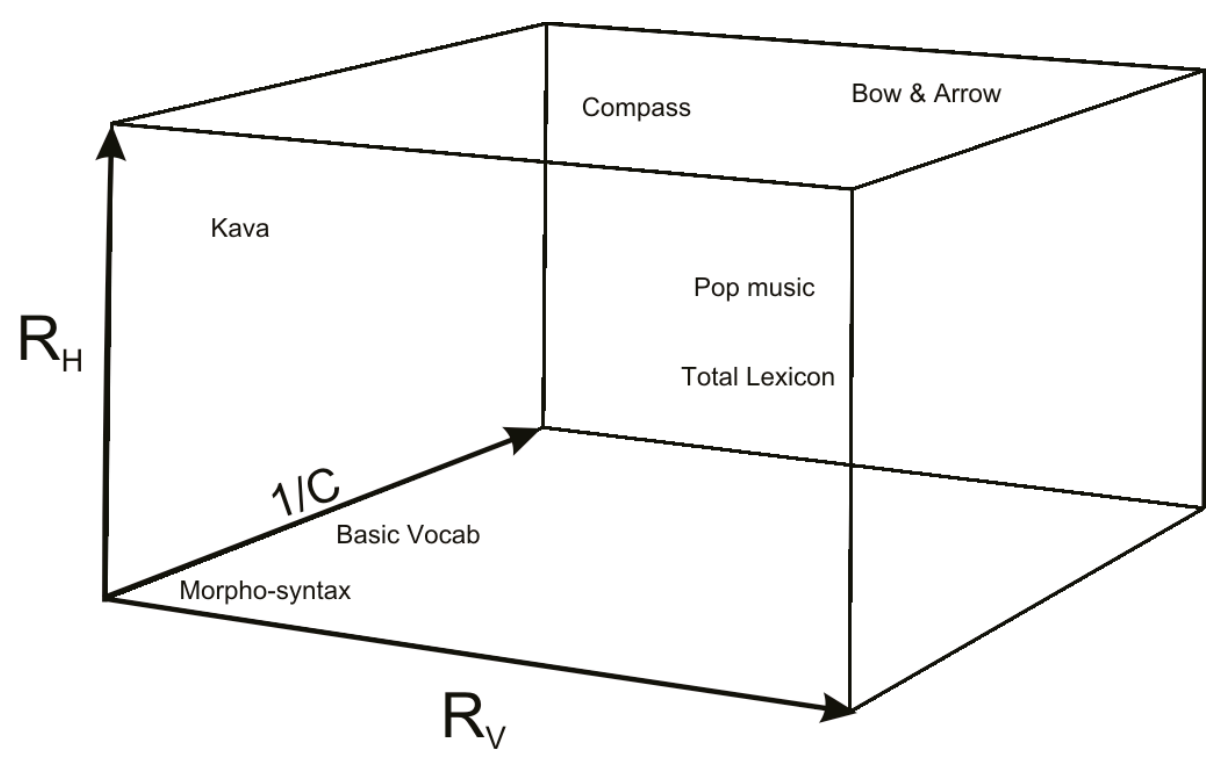

Figure 10: A three-dimensional space with different aspects of culture positioned along the dimensions. $R_{V}$ is the rate of change in characters transmitted vertically between generations, $R_{H}$ is the rate of horizontal transmission, and $C$ is the extent to which different aspects of culture are coupled together.

Figure 10 shows some examples of cultural traits crudely located in this three-dimensional space. Basic vocabulary (the words we use most often) evolve more slowly and with less borrowing than a random sample from the total lexicon. There is a saying in dialectology that, "every word has its own history" (Bloomfield 1935: 328). This may be true, but the histories of basic vocabulary words are likely to be much more coherent than those in the total lexicon. Many linguists think that morpho-syntax is the most stable, most coherent, and least borrowed aspect of language (Nichols 1992). This contrasts with cultural complexes like Kava ceremonies that evolve slowly and are moderately coherent but can be readily borrowed. Pop music evolves rapidly and contains some strong coherent traditions, but some of these traditions can be borrowed and easily combined. Finally, discrete technological innovations like a bow and arrow or a compass will be less tightly coupled to other aspects of culture and borrowed at a high rate. Cleary, there are other dimensions that could be added to this scheme (such as dimensions for the geographic and temporal pattern of borrowing) but we think that these three provide a useful way forward for conceptualizing debates about cultural phylogenies.

We feel that for progress to be made in debates about cultural evolution it would be of considerable value to estimate where in this three-dimensional space different aspects of cultural lie. How can $R_{v}, R_{h}$ and $C$ be estimated? In cases where cultural evolution is relatively treelike, $\mathrm{R}_{\mathrm{v}}$ can be estimated using the approach taken by Pagel et al. (2007) to study rates of word evolution. Using this method, cultural traits can be mapped onto a tree or sample of trees that reflect population history. The rate of change of the cultural trait can then be estimated and 
expressed in terms of its half-life provided that those trees can be dated. We suggest that many linguistic traits - such as basic vocabulary, phonological innovations and morpho-syntax - are likely to provide reasonable estimates of the population history because of cross generational transmission constraints. Trees constructed from these linguistic characters would therefore make good candidate trees from which to estimate the rates of change of other cultural traits such as material cultural and social organization.

The estimation of $\mathrm{R}_{\mathrm{h}}$ is a little less direct. The traditional phylogenetic measures of how well characters fit on trees - the consistency index and retention index - are inadequate because processes other than borrowing, such as convergent evolution and character loss, will also affect them. Instead, we suggest the following approach. First, the cultural data should be analyzed using an algorithm that does not assume a tree. For example, the NeighborNet method (Bryant and Moulton 2002) provides a useful visual summary of the extent to which the data are treelike and is thus an excellent starting point for studying borrowing. However, boxlike regions on the NeighborNet can be produced by parallel and convergent evolution as well as by horizontal transmission. Therefore, to estimate the relative roles of borrowing versus parallel and convergent evolution, the history of the individual characters responsible for conflicting signal needs to be studied carefully. We suggest that Bayesian phylogenetic mixture models (Pagel and Meade 2004) could be used to investigate complex histories at the level of specific characters. Instead of forcing all the characters onto a single tree, these mixture models allow different models of evolution to be applied to each character in the data. Essentially this allows the characters to "choose" between alternative trees. A multiple topology mixture model is currently implemented in Bayes Phylogenies (Pagel and Meade 2004) but, to the best of our knowledge, has not yet been used in studies of cultural evolution. The analysis of complex cultural histories is no easy task. In and of themselves, the results of such analyses will not necessarily discriminate between sources of conflicting signal such as borrowing and parallel changes. In situations where numerous characters support alternative topologies then some systematic process such as borrowing is more probable than numerous independent parallel changes. When the character patterns are less clear, external evidence (such as geographic proximity of possible donor cultures) could aid inferences about the relative likelihood of borrowing versus parallel or convergent evolution.

$\mathrm{C}$, the extent to which cultural lineages cohere on a common history could be measured in a number of ways. The simplest approach would be to use tree comparison metrics, such as the quartets metric (Day 1986), to quantify the difference between the phylogenies of different cultural traditions. One could also ask if two data sets significantly support different histories, since the topologies might be different but the phylogenetic support for these differences might be weak. This could be done in a parsimony framework using the partition homogeneity test (Farris et al. 1995), or in a Bayesian framework by calculating Bayes factors for the partitioned versus the non-partitioned data (Nylander et al. 2004; Suchard et al. 2003). The methods above require the a priori specification of partitions, which is problematic in cases where there are no plausible hypotheses about where these partitions should occur. However, methods that can identify pattern heterogeneity, such as the aforementioned mixture models (Pagel and Meade 2004), do not require a priori partitioning of data, and are thus ideally suited for the analysis of complex histories.

Reconciliation analysis, and an associated variant that incorporates horizontal transfers called "Jungles" (Page and Charleston 1998), have the potential to produce the most detailed inferences about the coupled history of different cultural lineages. These approaches estimate the number of duplication, lineage sorting, and horizontal transfer events required to reconcile incongruent trees. In Figure 8, we showed an example where one horizontal transfer and two lineage sorting events were required to reconcile two word trees. This approach could be applied much more generally 
to cultural evolution and would provide a useful way of investigating the processes that produce coherent cultural lineages. For example, trees based on material culture or social structure could be reconciled with trees based on linguistic or genetic data. Ultimately, this approach could be used to determine the relative roles of intrinsic social processes such as shared worldviews or "systems of meaning" (Boyd et al. 1997), and extrinsic events, such as population expansions, in generating coherent lineages. The estimation of appropriate relative costs to put on duplication, lineage sorting and horizontal transfer events will be a challenge to such analyses that may once again require the use of external evidence to narrow the space of most likely scenarios.

This brings us to a more general point: historical inferences are at their most powerful when multiple lines of evidence can be brought to bear on specific cases. One of the advantages of studying cultural evolution over biological evolution is that historical inferences can be "triangulated" (Kirch and Green 2001) using data from anthropology, archaeology and linguistics. An excellent example showing this triangulation pertains to the simple one-piece fishhook commonly found in Eastern Polynesia but absent from Western Polynesia. Naïvely, one might assume that this fishhook type was invented in Eastern Polynesia; however, as Kirch and Green demonstrate, linguistic evidence suggests that ancestral Polynesian society had a reconstructable term, *mataqu, for this kind of fishhook. On the basis of this evidence they inferred that ancestral Polynesia had the one-piece fishhook, and that it was subsequently lost in Western Polynesia - an inference that has subsequently been verified archaeologically (Kirch and Green 2001).

In the future we expect that external evidence such as geographic proximity, physical accessibility, known ancestral forms and temporal information from archaeology will increasingly be triangulated to help resolve questions and make inferences about complex cultural histories. As David Hull noted, "one should not expect more of a theory of sociocultural evolution than one does of a theory of biological evolution" (Hull 1982: 277). The prospect of future empirical work, combined with the dimensional approach and the methods we have outlined, make us optimistic that we can actually anticipate rather a lot.

\section{Acknowledgments}

We would like to thank Roger Green for useful discussion and anthropological insight, Peter Godfrey-Smith for sending us his unpublished manuscript, Werner Callebaut for his patience, and two anonymous reviewers for their insightful comments. 


\section{References}

Aberle DF (1961) Matrilineal descent in cross-cultural comparison. In: Matrilineal Kinship (Schneider D, Gough K, eds), 655-70. Berkley: University of California Press

Atkinson QD, Gray RD (2006) How old is the Indo-European language family? Progress or more moths to the flame? In: Phylogenetic Methods and the Prehistory of Languages (Forster P, Renfrew C, eds), 91-109. Cambridge: McDonald Institute for Archaeological Research.

Atkinson QD, Meade A, Venditti C, Greenhill SJ, Pagel M (in press) Languages evolve in punctuational bursts. Science.

Atkinson QD, Nicholls G, Welch D, Gray RD (2005) From words to dates: Water into wine, mathemagic or phylogenetic inference? Transactions of the Philological Society 103: 193-219.

Aunger R, ed (2000) Darwinizing Culture: The Status of Memetics as a Science. Oxford: Oxford University Press.

Bakker P (1997) A language of our own: The genesis of Michif, the mixed Cree-French language of the Canadian Métis. New York: Oxford University Press.

Bateman R, Goddard I, O'Grady R, Funk VA, Mooi R, Kress WJ, et al. (1990) Speaking of forked tongues: The feasibility of reconciling human phylogeny and the history of language. Current Anthropology 31: 1-24.

Bellwood P (2005) First Farmers: The Origins of Agricultural Societies. Malden: Blackwell Publishing.

Bellwood P, Renfrew C, eds (2003) Examining the Farming/Language Dispersal Hypothesis. Cambridge: McDonald Institute for Archaeological Research.

Bloomfield L (1935) Language. London: Allen \& Unwin.

Blust RA (1999) Subgrouping, circularity and extinction: Some issues in Austronesian comparative linguistics. In: Selected Papers from the Eighth International Conference on Austronesian Linguistics (Zeitoun E, Jen-kuei Li P eds.), Vol. 1: 31-94. Tapei, Taiwan: Academia Sinica.

Blust RA (2000) Why lexicostatistics doesn't work: The 'universal constant' hypothesis and the Austronesian language. In: Time Depth in Historical Linguistics (Renfrew C, McMahon A, Trask T, eds), Vol. 2: 311-331. Cambridge: McDonald Institute for Archaeological Research.

Borgerhoff Mulder M (2001) Using phylogenetically based comparative methods in anthropology: More questions than answers. Evolutionary Anthropology 10: 99-111.

Boucher Y, Douady CJ, Papke RT, Walsh DA, Boudreau MER, Nesbø CL, Case RJ, Doolittle WF (2003) Lateral gene transfer and the origins of prokaryotic groups. Annual Review of Genetics 37:283-328.

Boyd B (in preparation) On the Origin of Stories: Evolution Cognition and Fiction.

Boyd R, Borgerhoff Mulder M, Durham WH, Richerson PJ (1997) Are cultural phylogenies possible? In: Human by Nature, Between Biology and the Social Sciences (Weingart P, Richerson PJ, Mitchell SD, Maasen S, eds), 355-386. Mahwah, NJ: Lawrence Erlbaum Associates.

Bragg M (2003) The Adventure of English: The Biography of a Language. London: Hodder \& Stoughton.

Brown DDG, Bick M (1987) Religion, class, and context: Continuities and discontinuities in Brazilian Umbanda. American Ethnologist 14: 73-93.

Bryant D, Filimon F, Gray RD (2005) Untangling our past: Languages, trees, splits and networks. In: The Evolution of Cultural Diversity: A Phylogenetic Approach (Mace R, Holden CJ, Shennan SJ, eds.), 67-83. London: UCL Press.

Bryant D, Moulton V (2002) Neighbor-Net, an agglomerative algorithm for the construction of phylogenetic networks. In: Algorithms in Bioinformatics: Second International 
Workshop, WABI 2002, Rome, Italy, September 17-21: proceedings (Guigo R, Gusfield D, eds), 375-391. Berlin: Springer.

Campbell L (2004) Historical Linguistics, 2nd ed. Edinburgh: Edinburgh University Press.

Charleston MA (2003) Recent results in cophylogenetic mapping. Advances in Parasitology 54: 303-330.

Clifford J, Marcus G, eds (1986) Writing Culture: The Poetics and Politics of Ethnography. Berkeley: University of California Press.

Collard M, Shennan SJ, Tehrani JJ (2006) Branching versus blending in macroscale cultural evolution: A comparative study. In: Mapping Our Ancestors (Lipo CP, O'Brien MJ, Collard M, Shennan SJ, eds), 53-88. New Brunswick: Aldine Transaction.

Collard M, Tehrani, J (2005) Phylogenesis versus ethnogenesis in Turkmen cultural evolution. In: The Evolution of Cultural Diversity: A phylogenetic Approach (Mace R, Holden CJ, Shennan SJ, eds), 109-132. London: UCL Press.

Crowley T (1994) Proto who drank kava? In: Austronesian Terminologies: Continuity and Change (Pawley AK, Ross MD, eds), 87-100. Canberra: Pacific Linguistics.

Dagan T, Martin W (2006) The tree of one percent. Genome Biology 7(10): 118.111-118.117.

Dagan T, Martin W (2007) Ancestral genome sizes specify the minimum rate of lateral gene transfer during prokaryote evolution. Proceedings of the National Academy of Sciences 104: 870-875.

Darwent J, O'Brien MJ (2006) Using cladistics to construct lineages of projectile points from northeastern Missouri. In: Mapping Our Ancestors: Phylogenetic approaches in anthropology and prehistory (Lipo C, O'Brien MJ, Collard M, Shennan SJ, eds), 185-208. New Brunswick, N.J.: Aldine Transactions.

Darwin C (1859) On the Origin of Species. London: Murray

Darwin C (1871) The Descent of Man. London: Murray.

Day WHE (1986) Analysis of quartet dissimilarity measures between unidirected phylogenetic trees. Systematic Zoology 35: 325-333.

Dennett DC (1995) Darwin's Dangerous Idea: Evolution and the Meaning of Life. New York: Touchstone.

Diamond J, Bellwood P (2003) Farmers and their languages: The first expansions. Science 300: 597-603.

Dundes A, ed (1989) Little Red Riding Hood: A casebook. Madison, Wisconsin: University of Wisconsin Press.

Dunning Hotopp JC, Clark ME, Oliveira DCSG, Foster JM, Fischer P, Muñoz Torres MC, Giebel JD, Kumar N, Ishmael N, Wang S, Ingram J, Nene RV, Shepard J, Tomkins J, Richards S, Spiro DJ, Ghedin E, Slatko BE, Tettelin H, Werren JH (2007) Widespread Lateral Gene Transfer from Intracellular Bacteria to Multicellular Eukaryotes. Science 317: 1753-1756.

Durie M, Ross M (1996) The Comparative Method Reviewed: Regularity and Irregularity in Language Change. New York: Oxford University Press.

Ehrman BD (2005) Misquoting Jesus: The Story Behind Who Changed the Bible and Why. New York: HarperCollins.

Faith DP (1989) Homoplasy as pattern: Multivariate analysis of morphological convergence in Anseriformes. Cladistics 5: 235-258.

Farris JS, Källersjö M, Kluge AG, Bult, C (1995) Constructing a significance test for incongruence. Systematic Biology 44: 570-572.

Fitch WM (1970) Distinguishing homologous from analogous proteins. Systematic Zoology 19: 99-113.

Forster P, Renfrew C, eds (2006) Phylogenetic Methods and the Prehistory of Languages. Cambridge: McDonald Institute for Archaeological Research 
Fortunato L, Holden CJ, Mace R (2006) From bridewealth to dowry? A Bayesian estimation of ancestral states of marriage transfers in Indo-European groups. Human Nature 17: 355376.

Fowler CS (1983) Some lexical clues to Uto-Aztecan prehistory. International Journal of American Linguistics 49: 224-257.

Fracchia J, Lewontin RC (1999) Does culture evolve? History and Theory 38: 52-78.

Godfrey-Smith P (in press) Darwinian populations and transitions in individuality. In: The Evolutionary Transitions Revisited (Sterelny K, Calcott B, eds). Boston: MIT Press.

Goldman I (1970) Ancient Polynesian Society. Chicago: Chicago University Press.

Gottschall J, Wilson DS, eds (2004) The Literary Animal. Evanston, Illinois: Northwestern University Press.

Gould SJ (1987) An Urchin in the Storm. New York: W. W. Norton.

Gould SJ (1991) Bully for Brontosaurus. New York: Norton.

Gould SJ, Lewontin RC (1979) The spandrels of San Marco and the Panglossian Paradigm: A critique of the adaptationism programme. Proceedings of the Royal Society, Series B 205: 581-598.

Gray RD, Atkinson QD (2003) Language-tree divergence times support the Anatolian theory of Indo-European origin. Nature 426: 435-439.

Gray RD, Jordan FM (2000) Language trees support the express-train sequence of Austronesian expansion. Nature 405: 1052-1055.

Greenhill SJ, Blust R, Gray RD (2003-2007) The Austronesian Basic Vocabulary Database. From http://language.psy.auckland.ac.nz/

Greenhill SJ, Currie TE, Gray RD (in preparation) The effect of horizontal transmission on cultural phylogenies.

Greenhill SJ, Gray RD (2005) Testing population dispersal hypotheses: Pacific settlement, phylogenetic trees and Austronesian languages. In: The Evolution of Cultural Diversity: A Phylogenetic Approach (Mace R, Holden CJ, Shennan SJ, eds), 31-52. London: UCL Press.

Harvey PH, Pagel M (1991) The Comparative Method in Evolutionary Biology. Oxford: Oxford University Press.

Hill JH (2001) Proto-Uto-Aztecan: A community of cultivators in central Mexico? American Anthropologist 103: 913-934.

Holden CJ (2002) Bantu language trees reflect the spread of farming across Sub-Saharan Africa: A maximum-parsimony analysis. Royal Society London, Proceedings B 269: 793-799.

Holden CJ, Mace R (2003) Spread of cattle led to the loss of matrilineal descent in Africa: A coevolutionary hypothesis. Proceedings of the Royal Society, Series B 270: 2425-2433.

Holden CJ, Mace R (2005) 'The cow is the enemy of matriliny': Using phylogenetic methods to investigate cultural evolution in Africa. In: The Evolution of Cultural Diversity: A Phylogenetic Approach (Mace R, Holden CJ, Shennan SJ, eds), 217-234. London: UCL Press.

Hull DL (1982) The naked meme. In: Learning, Development, and Culture (Plotkin HC, ed), 273327. London: John Wiley.

Huelsenbeck JP, Rannala B (1997) Phylogenetic methods come of age: Testing hypotheses in an evolutionary context. Science 276: 227-232.

Huson DH, Bryant D (2006) Application of phylogenetic networks in evolutionary studies. Molecular Biology and Evolution 23: 254-267.

Jackson GB, Romney AK (1973) Historical Inference from cross-cultural data: The case of dowry. Ethos 1: 517-520.

Jordan P, Shennan SJ (2005) Cultural transmission in indigenous California. In: The Evolution of Cultural Diversity: A Phylogenetic Approach (Mace R, Holden CJ, Shennan SJ, eds), 133-164. London: UCL Press. 
Jordan P, Shennan SJ (2003) Cultural transmission, language and basketry traditions amongst the California Indians. Journal of Anthropological Archaeology 22: 42-74.

Kirch P, Green R (2001) Hawaiki, Ancestral Polynesia: An Essay in Historical Anthropology. Cambridge: Cambridge University Press.

Labov W (1994) Principles of Linguistic Change: Internal Factors. Oxford: Blackwell.

Labov W (2007) Transmission and Diffusion. Language 83: 344-387.

Lester L, Meade A, Pagel M (2005) The slow road to the eukaryotic genome. BioEssays 28: 57 64.

Lewontin RC (1970) The units of selection. Annual Review of Ecology and Systematics 1: 1-18.

Lipo CP, O'Brien MJ, Collard M, Shennan SJ, eds (2006) Mapping our Ancestors. New Brunswick and London: Aldine Transactions.

Lynch J (2002) Potent roots and the origin of kava. Oceanic Linguistics 41: 493-513.

Mace R, Holden CJ (2005) A phylogenetic approach to cultural evolution. Trends in Ecology and Evolution 20: 116-121.

Mace R, Holden CJ, Shennan SJ, eds (2005) The Evolution of Cultural Diversity: A Phylogenetic Approach. London: UCL Press.

Mace R, Pagel M (1994) The comparative method in anthropology. Current Anthropology 35: 549-564.

Maddison WP (1997) Gene trees in species trees. Systematic Biology 46: 523-536.

Mallet J (2005) Hybridization as an invasion of the gene. Trends in Ecology and Evolution 20: 229-237.

Mallory JP (1989) In Search of the Indo-Europeans: Languages, Archaeology and Myth. London: Thames \& Hudson.

Marck J (1996) The first-order anthropomorphic gods of Polynesia. Journal of the Polynesian Society 105: 217-258.

McMahon A, McMahon R (2005) Language Classification By Numbers. Oxford: Oxford University Press.

McWhorter J (2001) The Power of Babel. New York: Henry Holt/Times.

Mesoudi A, Whiten A, Laland KN (2004) Perspective: Is human cultural evolution Darwinian? Evidence reviewed from the perspective of The Origin of Species. Evolution 58: 1-11.

Moore JH (1994) Putting anthropology back together again: The ethnogenetic critique of cladistic theory. American Anthropologist 96: 925-948.

Murdock GP (1967) Ethnographic Atlas. Pittsburgh: University of Pittsburgh Press.

Nesse RM, Williams GC (1994) Why we get sick: The new science of Darwinian medicine. New York: Times Books.

Nichols J (1992) Linguistic Diversity in Space and Time. Chicago: University of Chicago Press.

Nunn CL, Borgerhoff Mulder M, Langley S (2006) Comparative methods for studying cultural trait evolution: A simulation study. Cross-cultural Research 40: 1-33.

Nylander JAA, Ronquist F, Huelsenbeck JP, Nieves-Aldrey JL (2004) Bayesian Phylogenetic Analysis of Combined Data. Systematic Biology 53: 47 - 67.

O'Hara RJ (1988) Homage to Clio, or, toward an historical philosophy for evolutionary biology. Systematic Zoology 37: 142-155.

Oppenheimer S, Richards M (2001) Slow boat to Melanesia? Nature 410: 166-167

Oxford English Dictionary, eds (2000) Oxford English Dictionary Online, 2nd ed 1989. Oxford: Oxford University Press.

Page RDM, Charleston MA (1998) Trees within trees: Phylogeny and historical associations. Trends in Ecology and Evolution 13: 356-359.

Pagel M (1994) Detecting correlated evolution on phylogenies: A general method for the comparative analysis of discrete characters. Proceedings of the Royal Society of London Series B, Biological Sciences 255: 37-45.

Pagel M (1999) Inferring the historical patterns of biological evolution. Nature 401: 877-884. 
Pagel M, Atkinson QD, Meade A (2007) Frequency of word-use predicts rates of lexical evolution throughout Indo-European history. Nature 449: 717-720.

Pagel M, Meade A (2004) A phylogenetic mixture model for detecting pattern-heterogeneity in gene sequence or character-state data. Systematic Biology 53: 571-581.

Pagel M, Meade A, Barker D (2004) Bayesian estimation of ancestral character states on phylogenies. Systematic Biology 53: 673-684.

Poole AM, Penny D (2006) Evaluating hypotheses for the origin of eukaryotes. BioEssays 29: 74-84.

Ross M (1996) Contact-induced change and the comparative method: Cases from Papua New Guinea. In: The Comparative Method Reviewed: Regularity and irregularity in language change (Durie M, Ross M, eds), 180-217. New York: Oxford University Press.

Ross M (1997) Social networks and kinds of speech-community event. In: Archaeology and Language: Theoretical and Methodological Orientations (Blench R, Spriggs M, eds), Vol 1: 209-261. London: Routledge.

Sanderson MJ (2002) Estimating absolute rates of evolution and divergence times: A penalized likelihood approach. Molecular Biology and Evolution 19: 101-109.

Spencer M, Davidson EA, Barbrook AC, Howe CJ (2004) Phylogenies of artificial manuscripts. Journal of Theoretical Biology 227: 503-511.

Sterelny K (2001) Niche construction, developmental systems, and the extended replicator In: Cycles of Contingency: Developmental Systems and Evolution (Oyama S, Griffiths PE, Gray RD, eds), 333-349. Cambridge, MA: MIT Press.

Sterelny K (2006a) The evolution and evolvability of culture. Mind \& Language 21: 137-165.

Sterelny K (2006b) Memes revisited. British Journal of Philosophy of Science 57: 145-165.

Suchard MA, Kitchen CM, Sinsheimer JS, Weiss RE (2003) Hierarchical phylogenetic models for analyzing multipartite sequence data. Systematic Biology 51: 649-664.

Swadesh M (1952) Lexico-statistic dating of prehistoric ethnic contacts. Proceedings of the American Philosophical Society 96: 453-463.

Swadesh M (1955) Towards greater accuracy in lexicostatistic dating. International Journal of American Linguistics 21: 121-137.

Tëmkin I, Eldredge N (2007) Phylogenetics and material cultural evolution. Current Anthropology 48: 146-153.

Terrell JE (1988) History as a family tree, history as an entangled bank: Constructing images and interpretations of prehistory in the South Pacific. Antiquity 62: 642-657.

Terrell JE, Kelly KM, Rainbird R (2001) Foregone Conclusions? In search of "Papuans" and “Austronesians". Current Anthropology 42: 97-124.

Thomason S, Kaufman T (1988) Language Contact, Creolization, and Genetic Linguistics. Berkeley: University of California Press.

Zipes JD (2006) Why fairytales stick: The evolution and relevance of a genre. New York: Routledge. 